\title{
La traducción social de la naturaleza. \\ La domesticación y la ingobernabilidad de los genes en la discusión sobre los organismos transgénicos
}

\author{
Jósean Larrión Cartujo \\ Universidad Pública de Navarra. Departamento de Sociología \\ josean.larrion@unavarra.es
}

Recibido: 03-10-2007

Aceptado: 09-06-2008

\section{Resumen}

Este trabajo muestra que la realidad supuestamente más indiscutible e innegociable de la naturaleza es interpretada de manera muy distinta por los múltiples actores individuales y colectivos que conforman las sociedades occidentales contemporáneas. Se analiza aquí una de las cuestiones centrales suscitadas en relación con la controversia general sobre la viabilidad humana y ambiental de los organismos modificados genéticamente (OMG). El problema inicial, en apariencia sencillo y fácilmente resoluble, de descubrir la representación única y verdadera de los productos transgénicos se convierte en un conflicto posterior mucho más amplio, profundo y enredado, consistente en establecer la contingente identidad natural y social de los OMG.

Palabras clave: controversias sociales, gestión del riesgo, función de los expertos, organismos modificados genéticamente.

Abstract. The social translation of nature. Domestication and ungovernability of genes in the controversy over transgenic organisms

The main aim of this article is to show that the reality of nature, supposedly most undeniable and unquestionable, is interpreted in very different manners by individual and collective actors, in contemporary western societies. This article addresses one of the key issues raised in relation to the general controversy over the human and environmental feasibility of genetically modified organisms (GMO). Although the initial problem of discovering a unique and true representation of transgenic products seems apparently simple and easy, it later becomes a broader, deeper and more complicated conflict, consisting in establishing the fluctuant natural and social identity of the GMO.

Key words: social controversies, risk management, expert's role, genetically modified organisms.

\section{Sumario}

Introducción Conclusión

1. El espacio de la domesticación Bibliografía

2. El espacio de la ingobernabilidad 


\section{Introducción}

Este trabajo relata una situación ciertamente ejemplar y significativa en la que se percibe con mucha precisión cómo la realidad supuestamente más indiscutible e innegociable de la naturaleza es interpretada de una manera muy distinta por los heterogéneos actores individuales y colectivos que conforman las sociedades occidentales contemporáneas. Su finalidad central consiste en abordar una de las cuestiones teóricas más importantes suscitadas en relación con la controversia general desatada en torno a la viabilidad humana y ambiental de estos híbridos sociales y naturales que son los organismos modificados genéticamente (OMG) (Latour, 1993; Callon y Rip, 1996). En él me ocupo en especial de la exposición y el análisis de la polémica científica y técnica medular, generada sobre todo con arreglo a qué debe considerarse que representa la, en cierto modo dúctil, flexible y maleable, categoría cognitiva de gen. Así, investigo qué supone la mayoría de los especialistas involucrados en este debate concreto que son tanto los genes como los transgenes. En este estudio, por tanto, similarmente a otras muchas situaciones complejas y polémicas donde también están presentes los riesgos, las ambivalencias y las incertidumbres asociados a la actual tecnociencia, me interrogo en particular acerca de qué tipo de identidad y de comportamiento específico se considera que debe atribuirse a los distintos genes y grupos de genes (Blanco e Iranzo, 2000; López Cerezo y Luján, 2000).

Con este propósito fundamental, por consiguiente, persigo examinar y esclarecer las posiciones sociales prácticas y discursivas más habituales y representativas existentes, tanto a favor como en contra de la libre proliferación mundial de los OMG (Herrera Racionero, 2004; Mendiola, 2006). Pues, como ya se ha señalado, si la materia prima principal de la revolución industrial pudo ser el petróleo, la materia prima más importante de la así llamada tercera revolución verde serían los propios genes (García Olmedo, 1998; Rifkin, 1999). No obstante, la discusión científica y técnica más relevante que se esfuerzan en resolver los múltiples expertos aquí implicados consiste, en gran medida, en dilucidar tanto la definición correcta de los genes y los transgenes, como la definición más adecuada de sus posibles interacciones teóricas y prácticas con el complejo y cambiante entorno intracelular y extracelular. Se observa mejor, en consecuencia, cómo el problema inicial, sólo en apariencia muy sencillo y fácilmente resoluble, de descubrir para siempre la definición única y verdadera de los novedosos productos transgénicos considerados en cuanto tales, se convierte poco a poco en un conflicto posterior mucho más amplio, profundo y enredado, consistente en establecer, de una forma sólida, duradera y resistente, la contingente identidad natural y social de los OMG (Charvolin y Schwartz, 1996).

A modo de introducción, por tanto, puede resultar aclaratorio indicar que este forcejeo científico y técnico particular radica sobre todo en consensuar, de un modo más o menos dialogado, la respuesta a la siguiente disyuntiva medular. Por un lado, pues, podemos dar por sentado que la concepción domi- 
nante en el campo disciplinario de la biología más ortodoxa sostiene en esencia que los genes son unas entidades naturales muy estables que actúan de una manera relativamente aislada y predecible. Por otro lado, en cambio, resulta también razonable expresar, a modo de síntesis, que la concepción alternativa propia de la biología más crítica con tales postulados afirma, en el fondo, que los genes son unas entidades no humanas muy abiertas y flexibles que interactúan de un modo complejo, cambiante y constante, tanto entre sí mismas como con el entorno ambiental en general. Así, la labor principal de esta reflexión sociológica consiste en mostrar hasta qué punto las múltiples controversias científicas y técnicas singulares suscitadas en torno al conocimiento y la evaluación de las posibles consecuencias humanas y ambientales adversas, derivadas de la libre proliferación mundial de los productos transgénicos, germinarían y se consolidarían con arreglo a la discusión científica y técnica más particular generada acerca de qué tipo de aliado no humano se supone que es un gen o un transgén (Callon, 1995; Callon y Rip, 1996).

Por consiguiente, la existencia de esta disputa teórica específica no debería sorprender en exceso a un observador razonablemente crítico, reflexivo e informado. De hecho, si inicialmente cabe describir y analizar las discusiones particulares más tensas generadas sobre la economía, la política y la sociedad, después cabe preocuparse también con similar rigurosidad acerca de las discusiones más importantes sobre la ciencia y la tecnología existentes en torno a la libre proliferación mundial de los OMG. En virtud de esta voluntad para seguir el rastro a la controversia sobre la liberación de los organismos transgénicos allí por donde se tornara acertado y conveniente, por ende, constituye un hecho bien significativo que el propio concepto de gen no sería, cuando menos de momento, una categoría cognitiva muy nítida, cerrada o consolidada, sino más bien una categoría científica y técnica en gran medida incierta, líquida y flexible todavía sin solidificar o estabilizar (Latour y Woolgar, 1995).

En consecuencia, una mirada sociológica bien atenta y entrenada permite aventurar ya que lo que aquí estaría en juego no sería únicamente la exclusiva y restringida identidad científica y técnica de los mismos genes o de los propios organismos transgénicos. Así, lo que estaría todavía por decidir en este difícil y escabroso escenario sería también, antes y sobre todo, la contingente identidad estática y dinámica de todos aquellos científicos y técnicos expertos, en particular, y de todos aquellos colectivos sociales, en general, que interactúan, negocian y forcejean en el muchas veces tenso espacio de la economía, la política y la sociedad para apoderarse del monopolio de las representaciones científicas y técnicas legítimas, tanto de las posibles consecuencias adversas derivadas de los distintos alimentos transgénicos, como del mundo social y natural del que todo y todos formamos parte integrante (Bourdieu, 2003: 197-198).

\section{El espacio de la domesticación}

Es bien sabido que se han cumplido ya más de diez años desde la primera comercialización internacional de los cultivos modificados genéticamente 
(James, 2005). Así, el conjunto de los expertos partidarios de la libre expansión global de los organismos transgénicos y la generalidad de los grupos económicos, políticos y sociales que se sirven de los dictámenes oficiales de estos mismos especialistas proclaman al mundo la supuesta plena domesticación teórica y práctica de los genes y los transgenes (Callon, 1995). Con el fin principal de afianzar esta hipótesis tan arriesgada y contundente, precisamente, son movilizados diversos argumentos y razonamientos que encuentran buen acomodo también en los múltiples textos de iniciación a la ciencia normal que produce el denominado paradigma hegemónico de la nueva ingeniería genética (Kuhn, 1995: 51-67).

Estos recursos educacionales básicos y divulgativos sostienen, por ejemplo, que el código genético estaría inserto en unas estructuras que se hallarían en el interior de los núcleos de las células. Se indica, así, que estas estructuras se llaman cromosomas y que éstas estarían compuestas, sobre todo, por largas cadenas de ácido desoxirribonucleico (ADN) (Watson, 1994). Como se ilustra, pues, en estos materiales iniciáticos, sirviéndose en muchos casos de un gran número de dibujos y fotografías que ya a casi todos nos resultan familiares, el ADN tendría el aspecto de una doble hélice enrollada en forma de espiral. Así, los eslabones de la espiral de ADN estarían formados por cuatro pequeñas moléculas llamadas nucleótidos. Estas moléculas serían de cuatro tipos, esto es, adenina, guanina, citosina y timina. El ADN recombinante (ADNr) sería, por tanto, una secuencia nueva de $\mathrm{ADN}$ que habría sido creada por la unión de material genético con orígenes biológicamente diferenciados. Asimismo, de este tipo de recursos elementales, se desprende que un OMG sería aquel organismo cuyo material genético habría sido modificado de una forma artificial insertándole $\mathrm{ADN}$ de otro u otros organismos diferentes. En consecuencia, resultaría aquí un saber estabilizado que un OMG sería aquel organismo cuyo material genético habría sido modificado por la acción humana de una manera que no se produciría nunca con arreglo a las formas más tradicionales de selección o de cruzamiento genético (García Olmedo, 1998).

Oficialmente, podría decirse también que las investigaciones con $\mathrm{ADNr}$ se iniciaron como consecuencia de dos episodios que, retrospectivamente, se consideran ciertamente relevantes y significativos. Por un lado, en el año 1970, se produjo el descubrimiento de las denominadas enzimas de restricción. Estas enzimas serían parte de la defensa de las bacterias contra unos virus que las atacarían y que son conocidos, por lo general, como bacteriófagos. Las enzimas de restricción actuarían a modo de tijeras moleculares, cortando el ADN del virus en trozos antes de su replicación dentro de la bacteria y, por tanto, impidiendo su multiplicación. Lo interesante desde el punto de vista de la nueva ingeniería genética sería que, al parecer, cada enzima de restricción casi siempre cortaría por el mismo lugar en una molécula de ADN. Por otro lado, merecería recordarse que, en 1973, se produjo el primer experimento de inserción de genes como consecuencia del desarrollo de la habilidad para proceder al aislamiento y al transporte de dichos genes (López Cerezo y Luján, 2000: 141-149). 
En este contexto, pues, podría sostenerse que las nuevas técnicas del $\mathrm{ADNr}$ permiten la incorporación de diversos segmentos de $\mathrm{ADN}$ foráneo en los organismos progenitores respectivos. Para realizar esto, lo primero que debería hacerse es aislar un gen y extraerlo de un cromosoma. En segundo lugar, deberían hacerse las copias respectivas de ese mismo gen. Por último, en tercer lugar, debería introducirse ese gen concreto en el cromosoma de un nuevo organismo receptor. La nueva ingeniería genética haría referencia, por tanto, al conjunto de las técnicas que se utilizarían para construir las distintas moléculas de $\mathrm{ADNr}$ para luego introducirlas en el interior de las células foráneas receptoras (Pedauyé Ruiz, Ferri Rodríguez y Pedauyé Ruiz, 2000).

Como he señalado, en suma, el proceso de transferencia de los genes se compondría de dos fases principales. La primera fase, realizada en tubos de ensayo, consiste en la extracción de un segmento de $\mathrm{ADN}$ perteneciente a las células de un organismo donante. De lo que se trata en esta fase es de tomar el segmento de un gen de una cadena de $\mathrm{ADN}$, utilizando para ello unas enzimas específicas a modo de tijeras moleculares, para así cortar en los lugares precisos de la cadena de $\mathrm{ADN}$. Con posterioridad, se procede a la construcción de una molécula portadora, lo que se conoce habitualmente como un vector, que contendrá el gen que interesa transportar. La segunda fase consiste en implantar el vector, que por lo general son virus o plásmidos, en el interior del organismo receptor. El especialista utiliza, en este caso, las mencionadas tijeras moleculares a fin de abrir un espacio en el vector que va a utilizar para introducir el gen de interés en la célula receptora. Debido a que los extremos cortados son adherentes en un sentido químico, tanto en el plásmido como en el segmento de gen, estos extremos se unen formando un nuevo plásmido que contiene el nuevo gen. Para completar el proceso, los científicos y técnicos utilizan otra enzima para garantizar que el nuevo gen quede bien fijado en el lugar deseado.

El poderoso ingenio de la condición humana permitiría, así, que las barreras naturales que existen, al parecer, entre las distintas especies fueran en principio triunfantemente derribadas y superadas. Mediante la utilización de este tipo de mecanismos artificiales, se construirían, por tanto, organismos que contienen genes que habrían sido extraídos de unos organismos en principio muy diferentes y distanciados. Así, lo realmente sorprendente sería que estos procedimientos pueden llevarse a cabo tanto entre unas plantas de especies biológicamente no relacionadas, como entre un microorganismo, una planta o cualquier tipo de animal. Dicho en otras palabras, lo realmente relevante de este tipo de métodos sería que, gracias a ellos, se habrían sometido y sobrepasado las barreras naturales que, en principio, regirían los procesos de reproducción de los diversos seres vivos, pues, en condiciones naturales y al margen de estas novedosas prácticas, sólo habría sido posible hasta ahora la selección y el cruzamiento genético de los seres vivos pertenecientes a una misma especie vegetal o animal. Sin embargo, según evidenciaré, los grupos sociales partidarios de la libre proliferación mundial de los productos transgénicos sostienen en público que las técnicas de la nueva ingeniería genética que habrían 
culminado de una manera muy triunfal y exitosa en la domesticación del gen, en modo alguno se opondrían a las leyes que operan, al parecer, en la misma naturaleza vegetal y animal.

Por consiguiente, la nueva ingeniería genética sería totalmente viable en virtud de una importante característica de la propia naturaleza. Esta propiedad esencial sería lo que se conoce con mucha frecuencia como la universalidad del código genético. Con lo cual, en respuesta a no pocas acusaciones, se proclama en público que estas nuevas prácticas en ningún caso se opondrían frontalmente al lenguaje más propio y característico de la naturaleza. Según ha señalado al respecto, por ejemplo, la Sociedad Española de Biotecnología (SEBIOT):

La ingeniería genética es un conjunto de técnicas que permiten alterar las características de un organismo mediante la modificación dirigida y controlada de su genoma, añadiendo, eliminando o modificando alguno de sus genes. Así, entre otras aplicaciones, la ingeniería genética permite eliminar una característica indeseable de un organismo (por ejemplo, la producción de una toxina) anulando el gen correspondiente de ese organismo. Igualmente permite introducir una nueva característica en una especie (por ejemplo, la resistencia a un insecto) copiando el gen correspondiente de una especie resistente a ese insecto e introduciéndolo en el genoma de la especie susceptible. Gracias a la universalidad del código genético, la ingeniería genética puede utilizar la información existente en todos los seres vivos. El intercambio de información genética entre distintos seres vivos no es una invención humana y ocurre con cierta frecuencia entre microorganismos (por ejemplo, bacterias) en la naturaleza. De hecho, la ingeniería genética se basa en mecanismos que operan normalmente en la naturaleza (SEBIOT, 2000: 7).

La finalidad central de estas prácticas no consistiría, pues, en caminar en contra de la propia naturaleza, sino más bien en controlar, corregir y ampliar los sólo aparentemente muy férreos e inmodificables límites asociados al lenguaje de dicha naturaleza. De esta forma, muchos de los especialistas partidarios de la nueva ingeniería genética argumentan que no sería cierto que, como sostienen algunos expertos y colectivos sociales detractores de estas nuevas técnicas, el hecho de saltarse las barreras naturales que existirían entre las distintas especies implicaría, de una manera casi necesaria, el surgimiento de posibles riesgos humanos o ambientales adversos y específicos. Así, los especialistas partidarios de los organismos transgénicos sostienen que todos los seres vivos que habitan en nuestro planeta participarían de un mismo patrimonio genético básico y fundamental. En opinión, por ejemplo, de José Ignacio Cubero, catedrático de genética en la Universidad de Córdoba:

La biotecnología representa un paso más en la mejora: la domesticación del gen, que termina, por ahora, el proceso de domesticación de especies y de variedades que comenzó con el nacimiento de la primera agricultura. Domesticación del gen que tiene dos interesantes repercusiones conceptuales: una, que desde el 
momento en que una bacteria es capaz de interpretar correctamente un gen humano y una planta de algodón el de una bacteria, se demuestra experimental y masivamente, y no sólo con cuidadosos ensayos planificados ad hoc, que todos los seres vivos tenemos acceso al mismo patrimonio genético: todos, pues, pertenecemos a una misma "familia". La segunda, que por la misma razón, esto es, por el hecho de que un gen de una planta silvestre puede expresarse correctamente en maíz, todo es recurso natural de todo, lo que le da a la conservación de la naturaleza una firme base objetiva y no puramente romántica (Cubero, 2000: 8-9).

Como ya he indicado, este supuesto teórico central afirma que la unidad de información genética básica estaría contenida plenamente en los genes particulares de los distintos organismos, de modo que los genes serían los portadores de la información biológica más esencial y relevante. Éstos serían considerados, por tanto, como trozos de $\mathrm{ADN}$ que portarían una serie de instrucciones extremadamente específicas en relación con el desempeño de funciones muy concretas y constantes. Se considera, en consecuencia, que los diferentes genes y grupos de genes podrían definir cada una de las diversas funciones del organismo en su nivel más relevante y fundamental. Asimismo, cada uno de los caracteres específicos de un organismo se encontraría registrado en forma de código en cada gen o grupo de genes particulares, con lo cual se entiende que la transferencia guiada de unos genes aislados y concretos de unos organismos a otros tendría como resultado único y necesario la transferencia de las funciones específicas supuestamente bien conocidas y controladas.

En coherencia, y a modo de síntesis, el modelo del determinismo genético de los organismos sostiene, en primer lugar, que los múltiples genes que conforman a un organismo vivo tendrían unas funciones propias muy estables, específicas y poco menos que independientes del resto de los distintos factores intracelulares y extracelulares. En segundo lugar, se supone que los diferentes genes y grupos de genes concretos determinarían los distintos caracteres fenotípicos de una manera muy férrea, lineal y como causa única. Por último, en tercer lugar, se afirma que los genes serían unas entidades moleculares esencialmente estables y constantes y, por tanto, plenamente susceptibles de un sólido conocimiento científico y técnico que haría muy viables los respectivos procesos de gestión, evaluación y prevención.

En consecuencia, como he expresado, la tesis quizá más importante que defienden en público tanto los expertos como los grupos sociales partidarios de la nueva ingeniería genética afirma que el comportamiento de los genes y de los transgenes sería muy regular, constante y bien conocido. Así, se subraya de continuo que los posibles riesgos humanos y ambientales adversos asociados a la nueva ingeniería genética, de existir éstos, serían siempre perfectamente evaluables, predecibles y controlables. Por ese motivo, no existiría en realidad, al parecer, ningún argumento lo suficientemente sólido y justificado en virtud del cual los distintos expertos y las sociedades actuales en general debieran inquietarse o preocuparse. Como, por ejemplo, ha afirmado Pere Puigdomènech, investigador del Consejo Superior de Investigaciones Científicas (CSIC): 
La manipulación genética de las semillas, para conseguir especies que mejoren la producción y la calidad de los productos, comporta algunos posibles riesgos que son perfectamente controlables. [...] Los riesgos predichos en todos estos casos son muy remotos o fácilmente identificables. Existe una cantidad considerable de controles que se han llevado a cabo tanto en Europa como en Estados Unidos y que han demostrado la inocuidad de estas plantas y la inexistencia de riesgos intrínsecos a la tecnología [del ADNr] (Puigdomènech, 1997: 26).

Por supuesto, como en tantos otros casos igualmente complejos y polémicos vinculados a la actual tecnociencia, una de las banderas retóricas que más se enarbolan en este debate concreto es la poderosa y cautivadora bandera del saber, la razón y el progreso. Así, las distintas preocupaciones de una buena parte de la opinión pública serían consideradas del todo infundadas e injustificadas desde un punto de vista exclusivamente racional o empírico. Porque quienes se oponen a la nueva ingeniería genética, cierto es que, aunque no sean plenamente conscientes de ello, también se opondrían, según parece, a los avances mismos de la ciencia y la tecnología, de forma que oponerse a los productos de la nueva ingeniería genética equivaldría poco menos que a oponerse a la innovación, el desarrollo y el progreso del conjunto de las sociedades contemporáneas (Borlaug, 1999). La férrea oposición a los cultivos transgénicos se explicaría así sólo desde el supuesto central de la existencia de un conocimiento ciertamente nulo, deficiente o tergiversado, pues se mantiene que este tipo de preocupaciones científico-técnicas y políticosociales estaría fundado sobre todo en una muy mala comprensión real de las verdaderas prácticas realizadas con arreglo a los postulados básicos de la nueva ingeniería genética. En este sentido, se comprende bien que los representantes oficiales de la poderosa empresa transnacional Monsanto acusen a sus críticos más férreos y aguerridos de proceder con arreglo a unas actitudes tan poco nobles y respetuosas como las siguientes: «Divulgar información falsa, teorías vudú, vandalismo, oscurantismo, proferir continuas amenazas y resaltar supuestos peligros de las super-malas hierbas y de los alimentos Frankenstein» (Bruno, 1998: 39).

\section{El espacio de la ingobernabilidad}

Si los expertos partidarios de los organismos transgénicos proclaman al mundo la plena domesticación de los genes y de los transgenes, los colectivos de especialistas detractores de estos mismos productos afirman al público en cambio la notable ingobernabilidad teórica y práctica asociada a los distintos OMG (Callon, 1995). En coherencia, para los diferentes expertos y grupos sociales que se posicionan en contra de la nueva ingeniería genética, el anterior retrato del estado de la cuestión distaría mucho de corresponderse con la auténtica naturaleza de los hechos. Para éstos, por ejemplo, los productos transgénicos no representarían una evidente mejora genética, sino más bien una verdadera 
degradación genética de las distintas plantas y animales (Encyclopédie des Nuisances, 2000: 71-99).

En concreto, la característica más importante y preocupante de estos nuevos organismos sería que no habrían pasado por la prueba de la evolución natural y que, por tanto, éstos deberían considerarse como meros absurdos evolutivos. De este modo, uno de los argumentos más utilizados por estos grupos críticos sostiene que los alimentos transgénicos no serían científicamente viables y seguros, pues se denuncia que se desconocería en gran medida qué factores influirían en el funcionamiento adecuado de la totalidad de los genes que componen cada uno de los alimentos. Por todo ello, si parece casi indudable que, en la actualidad, no se dispondría del conocimiento suficiente acerca de qué son y cómo se comportan los distintos genes, resulta igualmente incuestionable que saltarse las barreras naturales que existirían entre las diferentes especies podría implicar graves consecuencias sociales y ambientales tan impredecibles como incontrolables (Bartra y otros, 2005). Como, por ejemplo, han indicado Gregorio Álvaro Campos y Jorge Riechmann:

Si bien la ingeniería genética es una herramienta potentísima para la manipulación de los genes, actualmente existe un gran vacío de conocimiento sobre el funcionamiento genético de la planta o el animal que se va a manipular. ¿Qué genes se activan y se desactivan a lo largo del ciclo vital del organismo, cómo y por qué lo hacen? ¿Cómo influye el nuevo gen introducido en el funcionamiento del resto del genoma? ¿Cómo altera el entorno el encendido o el apagado de los genes de la planta cultivada? Actualmente, todas estas preguntas se encuentran, en gran medida, sin respuesta (Álvaro Campos y Riechmann, 1998).

Lo que más preocupa aquí es, por tanto, la posible existencia de un enorme vacío de conocimiento. De acuerdo, pues, con la posición detractora de la nueva ingeniería genética, el conocimiento científico y técnico acreditado acerca del comportamiento real de los genes sería sumamente pobre, escaso y limitado. En este sentido, la mayoría de los expertos partidarios de la nueva ingeniería genética sostiene, por ejemplo, que en torno al 95\% del material genético de los distintos organismos vivos debería llamarse ADN inútil, ADN basura o ADN chatarra. Lo cual, aunque sólo sea por los propios conceptos empleados al respecto, únicamente debería entenderse al parecer como un acto de clara prepotencia científica y técnica, consecuencia sobre todo del desconocimiento generalizado acerca de la función real desempeñada por este tipo de material genético en relación con los otros genes y con la totalidad del organismo (Shiva, 2001: 41-43).

Asimismo, una de las hipótesis principales hechas públicas por los colectivos más críticos sostiene que la transferencia genética siempre podría originar toda una multitud de efectos desconocidos e indeseados (Spendeler y Carrasco, 2003). En consecuencia, el proceso por medio del cual se procede al traspaso de ADN de un primer organismo donante a un segundo organismo receptor con el que 
éste apenas podría guardar relación natural alguna, sería algo que estaría poco menos que abocado a provocar toda una serie de efectos imprevistos, parte de los cuales podrían ser humana y ambientalmente perjudiciales e irreversibles. Por ende, la predicción del comportamiento específico de los transgenes que han sido liberados al medio ambiente sería, cuando menos en la actualidad, una cuestión mucho más compleja y arriesgada de lo que piensa y defiende en público la mayoría de los expertos y de los grupos sociales partidarios de la nueva ingeniería genética. De hecho, se argumenta que se tendría un conocimiento tan limitado e insuficiente acerca de cómo un organismo se desarrolla en virtud de su composición en $\mathrm{ADN}$ que la aparición futura en los organismos transgénicos de unas consecuencias imprevistas e indeseadas podría resultar poco menos que lógica o inevitable. Con lo cual se pone de relieve que no se trataría tanto de dilucidar si surgirán o no en estos organismos unas consecuencias inesperadas y perniciosas, sino sobre todo de esclarecer dónde, cuándo y cómo surgirán éstas. Según ha señalado, por ejemplo, Carlos Sentís, profesor titular del área de genética en la Universidad Autónoma de Madrid:

Sin querer entrar más a fondo en otro buen número de incógnitas que rodean el funcionamiento del $\mathrm{ADN}$ génico y no génico, el panorama general que aparece nítidamente es nuestra ignorancia sobre el funcionamiento global de los genomas y nuestra imposibilidad para determinar cuál o cuáles pueden ser los efectos de un cambio en una de las partes del genoma, por ejemplo, la introducción de un transgén, sobre el organismo en su conjunto (Sentís, 2002a: 630).

El triunfal y glorioso espacio del saber humano quedaría ensombrecido entonces por el siempre mucho más preocupante e indeterminado espacio de la ignorancia y el desconocimiento. En opinión de los expertos partidarios del paradigma dominante de la nueva ingeniería genética, pues, el conocimiento esencial acerca del comportamiento real de los genes y los organismos ya habría sido adecuadamente descubierto y controlado. Sin embargo, como ya he mostrado, para los especialistas detractores de la libre proliferación mundial de los alimentos transgénicos, apenas se estaría comenzando a entender la complejidad enorme que caracterizaría a los propios genes y a su comportamiento interactivo con el entorno ambiental en general. En este sentido, uno de los supuestos más importantes en los que descansa la crítica a la nueva ingeniería genética expresa que la relación que existe entre los genes y las funciones de los organismos no sería tan lineal y determinante como declaran algunos de los expertos más crédulos y entusiastas (Ho, 2001). En virtud de este contraargumento, por tanto, se denuncia que la nueva biotecnología se apoyaría en una desfasada ciencia determinista y unidimensional que presupone erróneamente que las distintas funciones de los organismos estarían determinadas de una forma muy lineal y directa por uno o varios genes concretos. Como, por ejemplo, se advierte en una nota editorial incluida en el polémico número monográfico de la revista The Ecologist, si alguna ciencia reúne las condiciones para 
ser considerada racional y objetiva, esa ciencia no sería precisamente aquélla que promueven los científicos y los técnicos expertos que trabajarían al servicio de los intereses y los valores de las grandes empresas transnacionales ligadas al paradigma hegemónico de la nueva ingeniería genética: «Porque la demagogia es ciencia sólo cuando hablan Monsanto y las otras megacompañías» (The Ecologist, 1998: 3).

La idea clave aquí denunciada es, por tanto, que los genes y los transgenes no serían tan constantes e invariantes como algunos de los expertos más optimistas y apasionados habrían pensado y manifestado (Ho y Ching, 2004: 5556). Igualmente, la relevancia de la genética tradicional habría quedado muy cuestionada y desacreditada debido, en especial, al progresivo conocimiento de la enorme incidencia de los distintos factores organísmicos y ambientales. Por esta razón, se afirma que los múltiples genes y grupos de genes concretos no deberían ser manipulados de una manera tan arbitraria y precipitada sólo con la finalidad central de ponerlos al servicio de los diversos intereses económicos, políticos y sociales. En este sentido, como ya he señalado, uno de los supuestos fundamentales de la nueva ingeniería genética sería que cada uno de los caracteres específicos de un organismo se encontraría registrado en forma de código en cada uno de sus genes de una manera muy estable y concreta, de tal forma que la transferencia de unos genes específicos tendría como resultado único y necesario la transferencia de unas funciones muy bien conocidas y controladas. No obstante, diversos expertos han criticado que los múltiples estudios que parten de tales supuestos teóricos serían en exceso reduccionistas y simplificadores. Así, en estos trabajos, apenas se habrían tenido en cuenta las complejas interacciones intracelulares y extracelulares que influirían de una forma decisiva en el desarrollo de los caracteres y las funciones de los organismos. Según ha subrayado, por ejemplo, la conocida bióloga Mae-Wan Ho:

Lo que $[\ldots]$ muestran los descubrimientos de la nueva genética es que el gen por sí mismo no tiene una continuidad ni fronteras bien definidas, ya que la expresión de cada gen depende en última instancia de todos los otros genes en el genoma y está ligada a ellos. No existe una circulación de información en un solo sentido que procede desde el ADN al ARN y de allí a las proteínas y al resto del organismo, tal como concebía el dogma central. En cambio, la expresión de los genes está sujeta a instrucciones, modificaciones y ajustes, de acuerdo con los contextos ambientales, fisiológicos y celulares. Más aún, la secuencia de bases del ADN en los genes y el genoma está sujeta a pequeños y grandes cambios en el curso del desarrollo normal y como resultado de las perturbaciones ambientales (Ho, 2001: 132).

Justamente, según muchos de los expertos detractores de los productos de la nueva ingeniería genética, la modificación del medio que rodea a los genes podría provocar unas modificaciones en cadena en gran medida desconocidas y perjudiciales para la salud humana y el medio ambiente (Capra, 2003: 205263). Se afirma, así, que múltiples hallazgos científicos habrían refutado con claridad cualquier hipótesis respaldada por el tradicional modelo del determinis- 
mo genético de los organismos. La nueva ecología genética favorecería, entonces, una perspectiva científica mucho más holista y compleja en todo lo que atañe al conocimiento de la identidad y el comportamiento de los genes. El genoma, por tanto, no sería tan constante e invariable como se presuponía, sino que sería una entidad muy fluida y dinámica que interactúa de una manera permanente con toda la fisiología del organismo y el conjunto del medio ambiente. En palabras de la propia Mae-Wan Ho:

Existe [...] una seria incompatibilidad entre la concepción de la biotecnología de ingeniería genética (incluidos los beneficios y las riquezas que se proyecta obtener a partir de ella) y la realidad de la nueva genética. Básicamente, los ingenieros genéticos creen que manipulando los genes pueden resolverse todos los problemas importantes del mundo. Razonan que, dado que los genes determinan los caracteres de los organismos, al cambiar los genes apropiados, es posible diseñar organismos capaces de satisfacer todas nuestras necesidades. Esto sólo puede ser verdad si los genes determinan los caracteres de los organismos de un modo nada complicado, de manera que, al identificar un gen, puede predecirse un carácter deseable o indeseable, al cambiarlo, se modifica el carácter, y al transferirlo, se transfiere el correspondiente carácter de una vez para siempre. En otras palabras, la biotecnología de ingeniería genética sólo tiene sentido si se cree en el determinismo genético (Ho, 2001: 80).

La crítica a los productos de la novedosa biotecnología corre pareja, pues, con la crítica a los supuestos y a las implicaciones centrales de la concepción genocentrista más ortodoxa y tradicional (Khor, 2003). Un férreo y creciente cuestionamiento que, dicho sea de paso, no procede sólo de unos espacios científicos y técnicos relativamente ajenos al propio paradigma de la biología ortodoxa, pues éste proviene también de algunos de los autores que han estudiado, aceptado y compartido durante mucho tiempo los supuestos teóricos y metodológicos más importantes asociados a dicho paradigma dominante. Como ha indicado también el profesor de genética Carlos Sentís:

Uno de los pilares básicos del paradigma determinista es la relación causal entre la acción de los genes y el fenotipo como conjunto de caracteres observables de un organismo, de modo que un gen determina un carácter y sus variantes - alelos-, las variaciones de tal carácter. Sin embargo, si bien es cierto que los genes suelen tener consecuencias fenotípicas concretas en una especie en unas condiciones dadas, las relaciones funcionales entre genes y fenotipo son difíciles de desentrañar, ya que genes homólogos no especifican necesariamente estructuras y funciones homólogas en organismos distintos y, a la vez, dos estructuras homólogas pueden estar codificadas por genes no homólogos. Es decir, que la función genética depende de su propio entorno genómico (y quizá de otros factores), y que la supuesta independencia de acción de los genes es simplemente falsa: no son unidades independientes que determinan los caracteres, sino que el fenotipo surge de la interacción entre los genes y el resto del ADN en un contexto concreto, tanto celular como organísmico. Las consecuencias prácticas de este hecho implican que la manipulación genética, por ejemplo, la intro- 
ducción de un gen de otra especie, puede afectar no sólo al carácter que deseamos modificar o añadir, sino también a otros cuya observación, además, puede ser evidente o ser imposible —al menos, a corto plazo (Sentís, 2002a: 630).

Se afirma, en suma, que la capacidad científica y técnica para transferir determinadas características moleculares bien identificadas de un organismo vivo donante a otro receptor sería de momento ciertamente deficiente, limitada y arriesgada. Además, debería tenerse presente que la capacidad científica y técnica disponible en la actualidad para realizar este tipo de transferencias genéticas nunca constituiría una demostración suficientemente fiable de sistema alguno para predecir todos los posibles efectos adversos asociados a estos productos y procedimientos. De forma que cuando se ubicara un nuevo gen en el cromosoma de un organismo receptor cualquiera, se sabrían muy pocas cosas con plena seguridad acerca de las interacciones posibles de este nuevo gen transferido con la totalidad de la fisiología del nuevo organismo y con el medio ambiente en general. Éste sería, por tanto, el motivo central por el cual, en un gran número de ocasiones, habría sido muy complejo y arriesgado predecir y controlar las posibles repercusiones humanas y ambientales adversas derivadas de la transferencia de genes de un organismo donante a otro organismo receptor biológicamente no emparentado o en gran medida distinto y distanciado (Khor y otros, 1995: 7).

\section{Conclusión}

Una vez expuesto el debate teórico central suscitado acerca de qué tipo de aliado no humano se supone que son los genes, procedo, a continuación, a redactar algunas notas a modo de análisis y conclusión. En esta línea, una de las primeras cosas que merece ser puesta de relieve consiste en lo poco inocente y desinteresado que resulta la utilización de algunos de los conceptos, las categorías o las expresiones lingüísticas. Por ejemplo, cuando diversos expertos y actores sociales se sirven de la expresión ingeniería genética, aunque lo hagan de un modo más o menos intencional o estratégico, queda claro que éstos se apropian de un concepto con notables connotaciones positivas relativas a las ideas de control, precisión y seguridad. De modo que, con la utilización de este tipo de expresiones, se procura omitir los posibles elementos negativos de imprecisión, inseguridad, descontrol o incertidumbre que en muchos casos, como afirman los expertos y los colectivos sociales detractores de los productos transgénicos, también estarían presentes en la práctica real de las nuevas tecnologías del ADNr. En consecuencia, como ya han reconocido algunos de los expertos aquí implicados, en un caso se haría hincapié en el enorme saber, precisión y seguridad del ingeniero genético, mientras que en el otro caso esta imagen inicial de un científico casi omnisapiente y omnipotente sería desplazada por una imagen alternativa que mostraría poco menos que a un sastrecillo remendón que, sin un excesivo control, dominio o conocimiento solvente de la situación, se dedicaría a cortar y pegar diferentes segmentos de ADN (García Olmedo, 1998: 140-142). 
Igualmente, los especialistas y los grupos sociales partidarios de la nueva ingeniería genética acostumbran con mucha frecuencia a hablar de mejora genética para referirse a los diversos alimentos transgénicos obtenidos como consecuencia de la aplicación de estas novedosas técnicas de investigación y producción. Mientras, tampoco debe extrañar mucho que los expertos y los colectivos sociales detractores de estos nuevos cultivos procedan con frecuencia similar a movilizar conceptos tales como el de degradación genética o el de organismos empeorados genéticamente para referirse a, en principio, estos mismos productos y prácticas (Encyclopédie des Nuisances, 2000: 71-99). En este sentido, cabe señalar que, para los grupos detractores de los productos transgénicos, el conjunto de los múltiples organismos residentes en la naturaleza serían poco menos que biológicamente perfectos e inmejorables. Pues aquí se afirma que los organismos vivos más naturales o tradicionales habrían convivido durante varios cientos de miles de años con los positivos e imprescindibles procesos selectivos de la evolución y la adaptación al entorno ambiental. Sin embargo, para los colectivos partidarios de los productos transgénicos, la naturaleza presentaría en algunas ocasiones ciertas características de error o de imperfección que, en diversos casos, podrían ser realmente mejoradas, corregidas o subsanadas por la acción humana. En suma, y sin pretender profundizar aquí en las cuestiones éticas y normativas centrales relacionadas especialmente con la biotecnología humana, cabe interpretar que unos grupos defienden en público que buena parte de la humanidad sólo se dedicaría a degradar las cosas naturales ya existentes. Los otros colectivos, en cambio, proclaman que sería sólo la especie humana la encargada de rectificar las posibles imperfecciones cometidas por la naturaleza y de poner fin a esta obra de momento inacabada e imperfecta que sería la obra suprema de un ya muy secularizado Dios Creador (Rifkin, 1979).

Tampoco podría decirse, en rigor, que constituya un concepto realmente limpio, inocente o transparente el propio concepto medular de organismo modificado genéticamente (OMG). En EEUU, por ejemplo, diversas personas y colectivos sociales partidarios de este tipo de productos se habrían esforzado de manera notable en sustituir el concepto de OMG por los conceptos alternativos de novel foods, 'nuevos alimentos' o 'alimentos modernos'. Así, no haría falta ser un diestro experto en análisis del discurso ni poseer un espíritu especialmente despierto para percibir, por ejemplo, que el concepto de novel food resulta mucho menos alarmante e inquietante para el público en general que el mencionado concepto de OMG, pues parece obvio que el concepto de novel food apenas puede relacionarse de una forma directa con la manipulación o la modificación genética de los distintos alimentos vegetales y animales. Por supuesto, los asesores de imagen y los responsables de las campañas publicitarias de las distintas empresas aquí implicadas saben bien que la aludida expresión de manipulación genética no siempre es asociada por los consumidores reales y potenciales a prácticas indudablemente seguras, positivas y saludables. Otro tanto cabría señalar en relación con la estrategia empresarial de desplazar los conceptos de biotecnología y de ingeniería genética por el, en principio, mucho más neutro y atractivo concepto de ciencias de la vida. Claro que, si queremos 
ser rigurosos y simétricos en el análisis de esta singular polémica, debemos advertir igualmente que tampoco son plenamente asépticos ni aproblemáticos los usos sociales de expresiones tan recurrentes como las referidas a los cultivos naturales, los productos biológicos o los alimentos tradicionales (Khor y otros, 1995: 14).

Asimismo, en relación con la controversia general sobre la libre proliferación mundial de los OMG, quisiera recordar que la labor principal para este trabajo ha consistido en evidenciar que, de momento, no se habría consensuado de una manera dialogada qué tipo de aliado no humano se supone que son los genes y los transgenes. Lo que quiero expresar con esta idea clave es que el propio concepto de gen representa una categoría cognitiva abierta y flexible que, cuando menos de momento, aguarda ser solidificada o institucionalizada. De hecho, el propio escenario de incertidumbre científica se habría ampliado y propagado hasta la misma categoría de gen o de transgen, un escenario por cierto diagnosticado de incertidumbre también por una buena parte de los científicos y técnicos expertos implicados en esta misma controversia fundamental (Wolfenbarger y Phifer, 2000; Domingo Roig y Gómez Arnáiz, 2000). Además, las profundas discrepancias que se mantienen entre los distintos grupos de especialistas se extienden y se comunican fuera de las paredes de los propios laboratorios. Lo cual fomenta, en gran parte también, que los múltiples colectivos sociales encuentren razones bien poderosas y acreditadas para no abandonar un notorio estado psíquico de continua inquietud, desconfianza e intranquilidad (Cáceres Terán, 2004).

Lo más significativo sería entonces pensar que estamos ante una categoría lingüística que, en efecto, representa quizá la cuestión central y neurálgica de las polémicas particulares sobre la ciencia y la tecnología suscitadas en torno a la libre proliferación mundial de los OMG. Lo cual sería algo sustantivo, pues resulta que estoy exponiendo y analizando la discusión genérica sobre la libre circulación mundial de los distintos productos transgénicos y ciertamente los expertos y los actores sociales más relevantes implicados en esta disputa son, de momento, incapaces de consensuar de una forma dialogada qué son los genes, cómo se comportan entre sí o cómo se relacionan éstos con el entorno intracelular y extracelular imperante. Empero, lo más sustantivo desde el punto de vista de este análisis sociológico no consiste tanto en que no se sepa de momento qué tipo de aliado no humano se supone que es un gen, sino más bien en que el respectivo conocimiento científico y técnico acreditado acerca de qué se supone que es un gen sería una cuestión que todavía está por reinventar, negociar y estabilizar por los distintos expertos y por los diversos actores económicos, políticos y sociales implicados en este mismo debate fundamental (Theys y Kalaora, 1996: 9-35).

Así las cosas, unos expertos y colectivos sociales estarían convencidos de que realmente se poseería el control o el dominio de esta singular situación. Es decir, que ya se sabría muy bien qué tipo de aliados no humanos son los genes y los transgenes. Mientras, otros especialistas y grupos sociales se esforzarían sobre todo en poner de manifiesto todo el gran trabajo que al respecto 
todavía quedaría por realizar. Igualmente, unos investigadores sostienen en público que lo sabrían prácticamente todo acerca de los mecanismos que rigen la transferencia genética de las funciones de los organismos. Al mismo tiempo, otros expertos afirman con similar contundencia que el riesgo, la ambivalencia y la incertidumbre serían los auténticos protagonistas de este tipo de situaciones. De ahí que los primeros nieguen casi todo foco de posible ignorancia o incertidumbre. De ahí también que los segundos casi sólo posean la certidumbre plena de las muchas y enormes incertidumbres derivadas de la libre circulación mundial de los OMG. El nuevo actor no humano al que unos y otros grupos llaman transgén es, en unos contextos sociales, un aliado bien conocido y prometedor, mientras que en otros escenarios sociales es empero un adversario muy extraño, amenazante y desconcertante. Así, de un lado, se estaría en presencia de la retórica de la esperanza, es decir, de la retórica sobre la dominación y la emancipación progresiva de la naturaleza exterior. Del otro lado, en cambio, se estaría en presencia de la retórica del miedo, esto es, de la retórica sobre el riesgo, la ambivalencia y la incertidumbre acerca de las posibles consecuencias imprevistas e indeseadas derivadas de las mencionadas nuevas prácticas científicas y técnicas (Mulkay, 1993-1994). En consecuencia, ningún colectivo de expertos se avergonzaría de nada en absoluto, pues todos tendrían en común tanto hablar en nombre de la auténtica verdad de las cosas y los objetos, como intentar erigirse en los portavoces únicos y legítimos del mundo natural y social en el que todos vivimos, sobrevivimos y convivimos (Bourdieu, 2003; Latour y Woolgar, 1995).

Por ende, una de las cuestiones más importantes y complejas desde un punto de vista científico y técnico residiría en cómo dilucidar cuál debería ser la traducción de la realidad natural más adecuada, válida o verdadera. A modo de síntesis, sabemos ya que la visión inicial propia de la biología más ortodoxa y tradicional persiste en poner de relieve que la realidad biológica de un organismo sí podría ser entendida esencialmente como un intrincado proceso perfectamente reducible a la comprensión de sus distintas partes integrantes. En cambio, la visión biológica alternativa, que es de un corte notablemente más holístico, global y ecologista, se esforzaría en explicitar las enormes debilidades teóricas y metodológicas de esa visión primera de la realidad natural. Como, en sintonía con esta concepción crítica y revisionista, advierte, por ejemplo, la activista y ecologista Vandana Shiva:

[Los paradigmas del] determinismo genético y [del] reduccionismo genético van parejos. Pero la afirmación de que los genes son lo primario tiene más de ideología que de ciencia. Los genes no son entidades independientes, sino que constituyen partes que dependen de una entidad que forma un todo y que les da sentido. Todas las partes de una célula interactúan, y las combinaciones de genes son por lo menos tan importantes como sus efectos individuales en el desarrollo de un organismo (Shiva, 2001: 50).

Las palabras siguientes ilustran también los supuestos teóricos y los interrogantes más importantes que definen a este paradigma emergente que, depen- 
diendo por supuesto de los autores y de las tradiciones preexistentes, podría recibir provisionalmente las denominaciones de organicismo materialista, biología de sistemas o nueva ecología genética (Ho, 2001). Dice así el profesor Carlos Sentís:

En general, se pretende hacer que un organismo incorpore características útiles que no le son propias mediante la incorporación de un gen de otra especie que sí presenta ese carácter y esto se fundamenta en dos pilares teóricos: los genes tienen una función en sí mismos y determinan linealmente los caracteres, de modo independiente de cualquier otro factor interno o externo al organismo. Muy al contrario, lo que nos demuestran los recientes estudios en genética, biología celular, fisiología vegetal o microbiología es la complejidad de los seres vivos y su interdependencia del ambiente en que se desarrollan, pero sobre todo, que nuestro conocimiento es muy limitado e incompleto. De hecho, ahora que ya hemos desentrañado varios genomas completos, incluido el propio genoma humano, seguimos muy lejos de entender cómo funcionan en la organización de la vida. No conocemos los intrincados niveles de interrelación entre los genes, ni entre los genes y el resto del genoma ni, desde luego, cómo consiguen los seres vivos mantener la constancia de los caracteres que los definen a la vez que muestran una permanente adaptación a los continuos cambios en las condiciones ambientales (Sentís, 2002b: 56-57).

En consecuencia, de acuerdo con esta perspectiva teórica y metodológica que otorgaría una importancia mucho mayor a la totalidad, a la complejidad y a la interdependencia entre las diversas partes que conformarían los distintos sistemas naturales globales, el mismo científco afirma:

Es necesario abandonar la actitud reduccionista imperante por un enfoque que considere los organismos como sistemas y los estudie en su globalidad, asumiendo que los seres vivos, desde las bacterias hasta los multicelulares más complejos, viven en comunidad y en relación de interdependencia con el medio natural (Sentís, 2002a: 633).

Por una parte, esto es, del lado del paradigma hegemónico de la nueva ingeniería genética, las propiedades principales de la totalidad (los organismos) serían comprendidas y explicadas sobre todo en virtud de la suma de las propiedades de las partes (los genes). Por otra parte, es decir, del lado del paradigma emergente vinculado al organicismo materialista, la biología de sistemas o la nueva ecología genética, las propiedades más importantes de las partes (los genes) serían comprendidas y explicadas sobre todo con arreglo a las propiedades de la totalidad (los organismos). El problema central, problema sólo en principio exclusivamente científico y técnico, consiste en cómo dilucidar si, por un lado, debe concederse un mayor valor teórico y práctico a la comprensión y la explicación de cómo son y funcionan las diversas partes o unidades biológicas integrantes, como en el caso de los genes o los grupos de genes, o si, por el contrario, debe otorgarse tal relevancia a la comprensión y a la expli- 
cación de cómo son y cómo funcionan tanto los organismos vivos y los sistemas biológicos totales como los complejos procesos de interacción, interconexión e interdependencia de los cuales estos organismos y sistemas serían tanto las causas como las consecuencias.

Llegados a este punto de nuestra investigación, se explicita que quizá la idea más fecunda que la reflexión sociológica puede aportar para el solvente esclarecimiento de esta particular controversia consiste en preguntarse en todo momento acerca de quiénes ganan y quiénes pierden con la proliferación global de los OMG (Bartra y otros, 2005). El primer frente discursivo y práctico es el relativo a lo que hemos llamado el espacio de la domesticación, el cual asume que la naturaleza vegetal y animal debe ser esencialmente desafiada, sometida y rediseñada. El segundo frente es el relativo al espacio de la ingobernabilidad, el cual, en cambio, entiende a todos los efectos que la naturaleza vegetal y animal debe ser en gran medida respetada, admirada y venerada. La postura partidaria de la dispersión creciente de los productos transgénicos asigna a lo humano el control, el dominio y la seguridad, y por ello apela a la libertad, la flexibilidad y la desregulación. La posición detractora advierte además en el obrar humano el peligro, el descontrol y la incertidumbre y, por ende, hace un llamamiento a la precaución, la sostenibilidad y la responsabilidad. Así, el conflicto entre las distintas racionalidades y posiciones sociales es tan profundo y embrollado que incluso condiciona que la propia noción de precaución, más allá de su supuesta precisión y objetividad, pueda ser interpretada, aplicada y utilizada tanto desde un enfoque más limitado, restringido y reduccionista, como desde una perspectiva mucho más amplia, relacional y sistémica (Tàbara, Polo y Lemkow, 2003).

Frente a este tenso y oscuro escenario, nuestro análisis sociológico nos ha permitido esclarecer, desde un punto de vista teórico y empírico, que lo que aquí está ciertamente en disputa es la transcripción científica y técnica de la propia realidad social y natural (Bourdieu, 2003). Claro que la representación cognitiva recibe el nombre de auténtica traducción sólo si es generada por el grupo de pertenencia, pues si ésta es producida por el grupo de los humanos tenidos por adversarios, se percibe en esencia como una traición siempre perniciosa e intolerable (Callon, 1995). Justamente, los distintos expertos y grupos sociales compiten en el fondo por la traducción cognitiva y práctica más adecuada de esta categoría abierta y flexible que todavía es la categoría científica y técnica de gen. La ciencia social más crítica y rigurosa permite entender entonces que, con arreglo en gran medida a los intereses y a los valores relativos a los diversos paradigmas y a las distintas posiciones sociales aquí en continuo litigio, si unos colectivos proclaman las muchas consecuencias positivas derivadas de la plena domesticación de los cultivos transgénicos, los otros grupos respondan advirtiendo de las múltiples ambivalencias e incertidumbres asociadas a la imposible gobernabilidad total de dichos OMG (Wynne, 1997). Por consiguiente, resulta de enorme interés concluir estos párrafos reorientando nuestra mirada sociológica hacia cómo todos estos actores individuales y colectivos forcejean en el muy rentable y competitivo campo de bata- 
lla de la actual tecnociencia por el monopolio de las representaciones científicas y técnicas legítimas de la categoría cognitiva de gen en particular, pero mucho más ampliamente del conjunto de los seres vivos y de la totalidad de los elementos y las relaciones que definen a eso que las interpretaciones sociales menos críticas y reflexivas identifican, tácita y explícitamente, bajo esa expresión en ocasiones muy opaca y resbaladiza que sería la referida a la naturaleza de los hechos.

\section{Bibliografía}

Álvaro Campos, G. y Riechmann, J. (1998). «Más vale prevenir que curar». El País, 4 de febrero.

BARTRA, Armando y otros (2005). Transgénicos, ¿quién los necesita?. México: Grupo Parlamentario del Partido de la Revolución Democrática.

BlanCO, J. R. y IRANZO, J. M. (2000). «Ambivalencia e incertidumbre en las relaciones entre ciencia y sociedad». Papers, núm. 61, p. 89-112.

BORLAUG, Norman E. (1999). «Los ecologistas extremistas impiden erradicar el hambre». El País, 28 de octubre.

Bourdieu, Pierre (2003/2001). El oficio de cientifico. Ciencia de la ciencia y reflexividad. Barcelona: Anagrama.

BRUnO, Kenny (1998). «El fracaso del «marketing» de Monsanto». The Ecologist, The Monsanto Files. Can We Survive Genetic Engineering?, vol. 28, núm. 5, p. 39-45.

CÁCERES TERÁN, Johanna (2004). «El rechazo de la población europea a los alimentos transgénicos: ¿Un mito?». Quark, núm. 33, p. 24-30.

CALlON, Michel (1995/1986). «Algunos elementos para una sociología de la traducción. La domesticación de las vieiras y los pescadores de la bahía de Saint Brieuc», En: Iranzo Amatriaín, Juan Manuel y otros (eds.) (1995). Sociología de la ciencia y la tecnología. Madrid: CSIC, p. 259-282.

CALlON, M. y RIP, A. (1996/1992). «Humanos, no-humanos: Moral de una coexistencia». En: THEYS, J. y KALAORA, B. (eds.) (1996/1992). La Tierra ultrajada. Los expertos son formales. México: FCE, p. 111-123.

CAPRA, Fritjof (2003/2002). Las conexiones ocultas. Implicaciones sociales, medioambientales, económicas y biológicas de una nueva visión del mundo. Barcelona: Anagrama.

Charvolin, F. y SChwartz, C. (1996). «¿Una liberación peligrosa?». En: TheYs, J. y KalaORA, B. (eds.) (1996/1992). La Tierra ultrajada. Los expertos son formales. México: FCE, p. 85-90.

Cubero, José Ignacio (2000). «Historia de la biotecnología vegetal». Ponencia presentada en las I Jornadas sobre Productos Transgénicos en Agricultura, del 13 al 15 de noviembre de 2000.

Domingo Roig, J. L. y Gómez Arnáiz, M. (2000). «Riesgos sobre la salud de los alimentos modificados genéticamente. Una revisión bibliográfica». Revista Española de Salud Pública, núm. 74, 3, p. 255-261.

Encyclopédie des Nuisances (2000/1999). Observaciones sobre la agricultura genéticamente modificada y la degradación de las especies. Barcelona: Alikornio.

García Olmedo, Francisco (1998). La tercera revolución verde: Plantas con luz propia. Madrid: Debate.

González García, M. I.; López Cerezo, J. A. y Luján López, J. L. (eds.) (1997). Ciencia, tecnologia y sociedad. Lecturas seleccionadas. Barcelona: Ariel. 
Herrera Racionero, Paloma (2004). "Creer en los argumentos y argumentar las creencias. La "guerra de los OGMs"». En: VIII Congreso Español de Sociología. Alicante: Federación Española de Sociología, septiembre de 2004.

Ho, Mae-Wan (2001/1998). Ingeniería genética. ¿Sueño o pesadilla? Barcelona: Gedisa. Ho, M.-W. y CHING, L. L. (2004/2003). En defensa de un mundo sustentable sin transgénicos. Londres y Penang: Institute of Science in Society, Third World Network. IRANZO AMATRIAín, Juan Manuel y otros (eds.) (1995). Sociología de la ciencia y la tecnología. Madrid: CSIC.

JAMES, Clive (2005). Situación global de los cultivos transgénicos comercializados: 2005. Briefs 34, Ithaca, Nueva York: International Service for the Acquisition of AgriBiotech Applications (ISAAA).

KHOR, Martin y otros (1995). La necesidad de mayor reglamentación y control sobre la ingeniería genética. Declaración de científicos preocupados por las tendencias actuales en la nueva biotecnología. Jutaprint, Penang (Malasya): Red del Tercer Mundo. KHOR, Martin (2003). El saqueo del conocimiento. Propiedad intelectual, biodiversidad, tecnología y desarrollo sostenible. Barcelona: Icaria, Intermón Oxfam.

KuHN, Thomas Samuel (1995/1962-1969). La estructura de las revoluciones cientificas. México: FCE.

LATOUR, B. y WOOLGAR, S. (1995/1979-1986). La vida en el laboratorio. La construcción de los hechos cientificos. Madrid: Alianza.

Latour, Bruno (1993/1991). Nunca hemos sido modernos. Madrid: Debate.

López Cerezo, J. A. y Luján, J. L. (2000). Ciencia y política del riesgo. Madrid: Alianza. MENDIOLA, Ignacio (2006). El jardín biotecnológico. Tecnociencia, transgénicos y biopolitica. Madrid: La Catarata.

MULKAY, Michael (1993-1994). «Retórica y control social en el gran debate sobre los embriones». Política y Sociedad, núm. 14-15, p. 143-153.

Pedauyé Ruiz, J. y Ferri Rodríguez, A. y Pedauyé Ruiz, V. (2000). Alimentos transgénicos. La nueva revolución verde. Madrid: McGraw-Hill.

PuigdomèneCh, Pere (1997). «Semillas transgénicas». Vida Rural, núm. 50, p. 26-27.

RIFKIN, Jeremy (1979/1977). ¿Quién suplantará a Dios?. Madrid: Edaf.

RIFKIN, Jeremy (1999/1998). El siglo de la biotecnología. Barcelona: Paidós.

SEBIOT (2000). Plantas transgénicas. Preguntas y respuestas. Madrid: Artes Gráficas G3.

SeNTís, Carlos (2002a). «Ingeniería genética. Insuficiencias teóricas y la aplicación del principio de precaución». Política y Sociedad, vol. 39, núm. 3, p. 627-639.

SenTís, Carlos (2002b). «Transgénicos. Cara y cruz». El Cultural, de El Mundo, p. 56$57,22-28$ de mayo.

SHIVA, Vandana (2001/1997). Biopiratería: El saqueo de la naturaleza y del conocimiento. Barcelona: Icaria, Antrazyt.

Spendeler, L. y CARRASCO, J.-F. (2003). Al grano. Impacto del maíz transgénico en España. Alcobendas: Amigos de la Tierra y Greenpeace, Industrias Gráficas EPES.

TÀbARA, J. D.; POlO, D. y LEMKOW, L. (2003). «Precaución, riesgo y sostenibilidad en los organismos agrícolas genéticamente modificados». Política y Sociedad, vol. 40, núm. 3, p. 81-103.

The Ecologist (1998). "Nota editorial. Multinacionales y debate democrático». The Ecologist, The Monsanto Files. Can We Survive Genetic Engineering?, vol. 28, núm. 5, p. 3-4.

Theys, J. y Kalaora, B. (eds.) (1996/1992). La Tierra ultrajada. Los expertos son formales. México: FCE. 
THEYS, J. y KALAORA, B. (1996/1992). «Cuando la ciencia inventa de nuevo el medio ambiente». En: ThEYS, J. y KalaOra, B. (eds.) (1996/1992). La Tierra ultrajada. Los expertos son formales. México: FCE, p. 9-35.

WaTSON, James (1994/1968). La doble hélice. Un relato autobiográfico sobre el descubrimiento del ADN. Barcelona: Salvat.

Wolfenbarger, L. L. y Phifer, P. R. (2000). «The ecological risks and benefits of genetically engineered plants». Science, 290, p. 2088-2092, 15 de diciembre.

WYNNE, Brian (1997/1992). «Incertidumbre y aprendizaje ambiental. Reconcebir la ciencia y la política en un paradigma preventivo». En: GONZÁLEZ GARCÍA, M. I.; LÓPEZ CEREZO, J. A. y LuJÁn LOPEZ, J. L. (eds.) (1997). Ciencia, tecnología y sociedad. Lecturas seleccionadas. Barcelona: Ariel, p. 161-183. 